\title{
Utilização de biópsias da terceira pálpebra e mucosa retal em ovinos para diagnóstico de scrapie em uma propriedade da Região Sul do Brasil ${ }^{1}$
}

\author{
Juliano S. Leal' ${ }^{2}$, Gabriel L.F. Correa², André G.C. Dalto², Gisele S. Boos², Eduardo C. \\ Oliveira ${ }^{2}$, Paulo M. Bandarra², Rui F.F. Lopes ${ }^{3}$ e David Driemeier ${ }^{2 *}$
}

\begin{abstract}
Leal J.S., Correa G.L.F., Dalto A.G.C., Boos G.S., Oliveira E.C., Bandarra P.M., Lopes R.F.F. \& Driemeier D. 2012. [Use of third eyelid and rectal mucosa biopsies for diagnosis of sheep scrapie on a farm in Southern Brazil.] Utilização de biópsias da terceira pálpebra e mucosa retal em ovinos para diagnóstico de scrapie em uma propriedade da Região Sul do Brasil. Pesquisa Veterinária Brasileira 32(10):990-994. Setor de Patologia Veterinária, Faculdade de Veterinária, Universidade Federal do Rio Grande do Sul, Av. Bento Gonçalves 9090, Porto Alegre, RS 91540-000, Brazil. E-mail: davetpat@ufrgs.br

Scrapie, a form of transmissible spongiform encephalopathy (TSEs) is a fatal neurodegenerative disorder that affects sheep and goats. The disease is characterized by an accumulation of the abnormal prionic protein $\left(\mathrm{PrP}^{\mathrm{sc}}\right)$ in the encephalic and lymphoreticular tissues. This paper describes the use of anti-prionic protein immunohistochemical (IHC) procedure as a method of pre-clinical diagnosis of scrapie.The test was carried out in biopsied lymphoreticular tissues from third eyelid and rectal mucosa. Anti-prion protein monoclonal antibodies F89/160.1.5 and F99/97.6.1 were used. Scrapie diagnosis in lymphoreticular tissues through IHC was achieved when the samples had a minimum of three lymphoid follicles in well delimited germinal centre. Positive immunostaining was identified in 19 out of 318 samples of the third eyelid. Material sampled at post-mortem examination in 18 of these scrapie-positive sheep, which were previously verified by biopsy, and in 21 of its relatives, was confirmed with IHC tests. Positive immunostaining from rectal mucosa tissue was not observed. Third eyelid and tonsil were the organs with the larger amount of positive immunostaining (18/18 and 8/18 respectively) at post-mortem examination. None positive result was obtained along the 21 animals related to the positive ones, and none of the positive cases showed IHC labeling in the brain. The use of lymphoid tissues for scrapie diagnosis by IHC through biopsies showed to be a viable and efficient method for pre-clinical diagnostic.
\end{abstract}

INDEX TERMS: Sheep, scrapie, biopsy, lymphoid, immunohistochemistry.

RESUMO.- Scrapie é uma encefalopatia espongiforme transmissível (EET) que causa lesões cerebrais degenerativas em ovinos e caprinos. Caracteriza-se pelo acúmulo, no tecido encefálico e linforreticular, da forma anormal da proteína priônica $\left(\mathrm{PrP}^{\mathrm{Sc}}\right)$ que provoca a morte maciça de

\footnotetext{
${ }^{1}$ Recebido em 7 de junho de 2012.

Aceito para publicação em 26 de junho de 2012.

${ }^{2}$ Setor de Patologia Veterinária, Faculdade de Veterinária, Universidade Federal do Rio Grande do Sul (UFRGS), Av. Bento Gonçalves 9090, Porto Alegre, RS 91540-000, Brasil. *Autor para correspondência: davetpat@ufrgs.br

${ }^{3}$ Departamento de Ciências Morfológicas, Instituto de Ciências Básicas da Saúde, UFRGS, Av. Sarmento Leite 500, Porto Alegre, RS 90050-170.
}

neurônios e células gliais, além de vacuolização intensa no tecido afetado. Esse trabalho descreve a utilização da técnica de imuno-histoquímica (IHQ) para proteína priônica em tecido linforreticular de biópsias de terceira pálpebra e mucosa retal, como método diagnóstico de scrapie em ovinos. Realizaram-se exames de IHQ para scrapie em amostras de uma propriedade de origem de um ovino com diagnóstico dessa enfermidade. Utilizaram-se anticorpos monoclonais antipríon para diagnóstico ante mortem pela técnica de IHQ. Nas 318 amostras de biópsias analisadas, encontrou-se 19 resultados positivos para $\mathrm{PrP}^{\mathrm{Sc}}$ nos folículos de terceira pálpebra e não foi obtida marcação no tecido linfático de mucosa retal em nenhuma das amostras cole- 
tadas. Realizaram-se 18 necropsias dos animais positivos anteriormente por biópsia e 21 necropsias de ovinos parentes dos positivos de scrapie. Confirmou-se o resultado de scrapie pela IHQ após a necropsia dos animais positivos nas biópsias de terceira pálpebra. Nesses animais, os órgãos com maior número de cortes positivos foram a terceira pálpebra (18/18) e a tonsila (8/18). Nos ovinos com parentesco com os positivos, nenhum resultado de scrapie ocorreu. A utilização de tecidos linfoides no diagnóstico de scrapie por IHQ através de biópsias mostrou-se um método viável e eficaz para o diagnóstico pré-clínico.

TERMOS DE INDEXAÇÃO: Ovinos, scrapie, biópsia, linfoide, imuno-histoquímica.

\section{INTRODUÇÃO}

Scrapie é uma encefalopatia espongiforme transmissível (EET) que afeta ovinos e caprinos (Prusiner 1995). As características dessa doença incluem um longo e variável período de incubação (Wood et al. 1992) que é, provavelmente, afetado pela dose do agente infeccioso, idade do animal, genótipo do animal e da cepa da proteína priônica infectante $\left(\mathrm{PrPs}^{\mathrm{Sc}}\right.$ ) (Hoinville 1996, Hunter 1997, Fraser 2000, Billinis et al. 2002). Em ovinos, scrapie ocorre, principalmente, entre dois e cinco anos de idade (Fraser 2000). Há evidências de que, em rebanhos endemicamente infectados, scrapie é transmitido principalmente durante o período perinatal (Hoinville 1996). Scrapie provoca vacuolização neuronal e do neurópilo e a acumulação da forma anormal da proteína priônica $\left(\mathrm{PrP}^{\mathrm{Sc}}\right)$ no sistema nervoso central (SNC) ao contrário da proteína celular normal do hospedeiro ( $\mathrm{PrP}^{\mathrm{C}}$ ) (Prusiner 1982). A forma mais comum é a Forma Clássica de Scrapie e pode ser detectada precocemente em tecidos linfoides. Uma forma atípica, NOR 98, afeta ovinos com genótipo resistente para a forma clássica e tem se tornado comum na Europa (Andréoletti et al. 2011).

O diagnóstico de scrapie em ovinos com sinais clínicos é realizado pelo exame histológico com detecção de vacuolização neuronal e do neurópilo e mediante detecção imuno-histoquímica (IHQ) de $\operatorname{PrP}^{\mathrm{Sc}}$ no encéfalo de ovinos (Miller et al. 1993). A IHQ é particularmente útil para o diagnóstico de scrapie em ovinos no início do estágio clínico da doença, quando as alterações histológicas são leves, ou em casos com amostras com autólise inicial. A técnica também é útil para identificação do agente em ovinos na fase pré-clínica da doença pela detecção de $\mathrm{PrP}^{\mathrm{Sc}}$ em tecidos linfóides antes do envolvimento do SNC (Ikegami et al. 1991, Schreuder et al. 1998). Baseando-se nessa perspectiva, métodos de diagnósticos pré-clínicos de scrapie, utilizando-se biópsias de tonsila (Schreuder et al. 1998), terceira pálpebra (O’Rourke et al. 2000) e da mucosa retal (Gonzáles et al. 2008) são descritos para controle da enfermidade.

0 presente trabalho descreve a utilização da técnica de IHQ com a coleta de material por biópsias de terceira pálpebra e mucosa retal de ovinos para o diagnóstico de scrapie em uma propriedade da Região Sul do Brasil com a posterior necropsia dos animais positivos e parentes desses, como medida de controle da doença, e para análise e comparação da eficácia da técnica de IHQ em órgãos linfoides.

\section{MATERIAL E MÉTODOS}

Diagnósticos ante mortem de scrapie em ovinos foram realizados pelo Setor de Patologia Veterinária da Universidade Federal do Rio Grande do Sul (SPV-UFRGS) com a realização de biópsias de terceira pálpebra e mucosa retal em uma propriedade na Região Sul do Brasil. Essa propriedade foi responsável pela venda de um ovino da raça Suffolk que apresentou sinais clínicos e achados patológicos e imuno-histoquímicos que comprovaram scrapie.

Coletou-se fragmentos de tecido linfoide de terceira pálpebra e da mucosa retal de 318 ovinos através de biópsia para exame histológico e posterior IHQ para $\mathrm{PrP}^{\mathrm{Sc}}$. A avaliação histológica prévia ocorreu pela necessidade de ter no mínimo três folículos para posterior realização da IHQ de scrapie em órgãos linfoides.

Para efetuar as biópsias, os animais foram contidos por, pelo menos, um operador e os tecidos de terceira pálpebra e de mucosa retal foram coletados por outros dois operadores. Na coleta da terceira pálpebra, administrou-se colírio oftalmológico (Colírio anestésico ${ }^{\circledR}$, cloridrato de tetracaína $1 \%$ e cloridrato de fenilefrina 0,1\%, Laboratório Allergan, Brasil) no olho esquerdo. Em seguida, o tecido linfoide bulbar era visualizado sob a superfície interna da terceira pálpebra, como um tecido protuberante ligeiramente róseo, na porção medial dos olhos. A mucosa da terceira pálpebra foi pinçada, levemente tracionada para afastá-la do tecido conjuntivo subjacente e, com auxílio de uma tesoura curva Metzenbaum, realizou-se um corte para retirada da amostra (Fig.1).

Após a coleta de terceira pálpebra, utilizou-se outro conjunto de pinça e tesoura curva para excisão de um fragmento de mucosa retal, coletado aproximadamente a $2 \mathrm{~cm}$ cranial da linha de junção da mucosa reto-anal, ventralmente (Fig.2). Aplicou-se 0,5ml de cloridrato de lidocaína $2 \%$ sem vasoconstritor $\left(\right.$ Xylestesin ${ }^{\circledR}$, Laboratório Cristália, Brasil) na mucosa retal, com auxílio de um espéculo ginecológico de tamanho médio humano vagispec ${ }^{\circledR}$ introduzido no reto do animal. Após a coleta da amostra e a retirada do espéculo realizou-se a administração tópica de repelente, cicatrizante em aerosol (Bactrovet Prata $\mathrm{AM}^{\circledR}$, Laboratório König do Brasil).

As amostras de terceira pálpebra e de mucosa retal foram fixadas em formol tamponado $10 \%$ neutro durante 24 horas e processadas pelas técnicas de rotina histológica e subsequente coloração em hematoxilina-eosina (HE) (Fig.3). A detecção do príon pela técnica de IHQ ocorreu pelo método estreptavidina-biotina ligada à peroxidase. Inicialmente os cortes histológicos foram

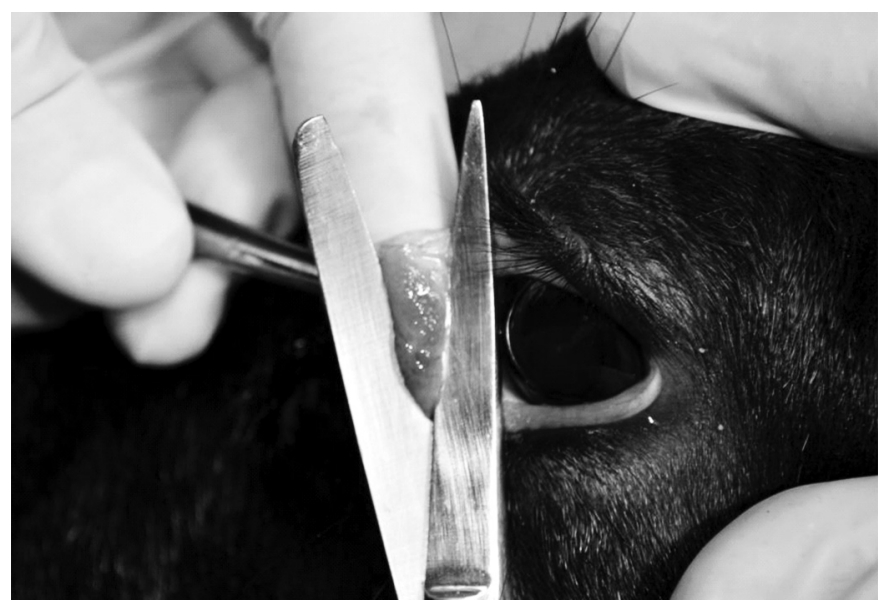

Fig.1. Técnica para coleta de biópsia de terceira pálpebra em ovino para imuno-histoquímica de scrapie. Exposição da terceira pálpebra com auxílio da fixação por pinça para retirada do tecido com tesoura. 


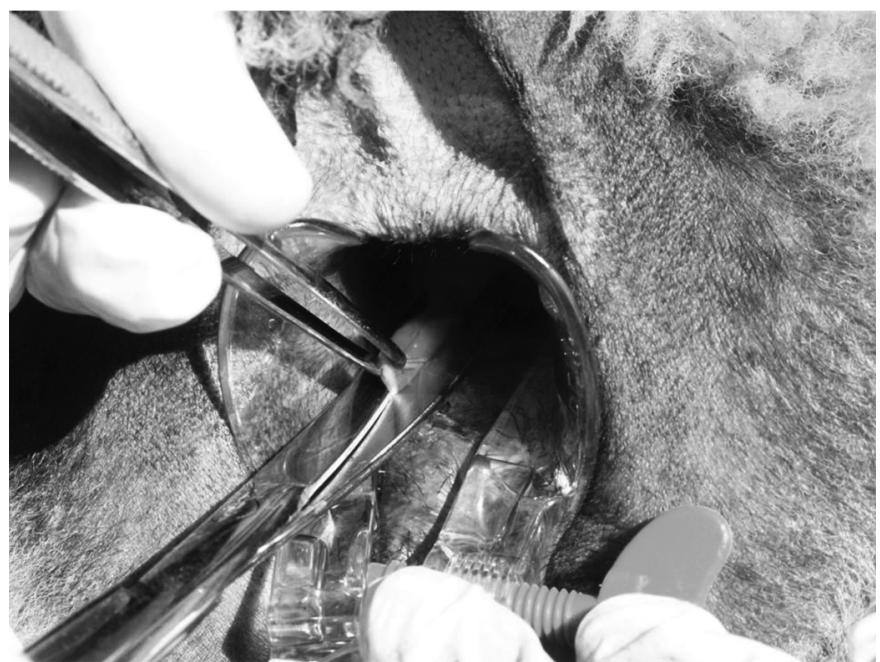

Fig.2. Técnica para coleta de biópsia de mucosa retal em ovino para imuno-histoquímica de scrapie. Exposição da mucosa retal com auxílio de espéculo, após anestesia local, pinçamento e corte com tesoura.

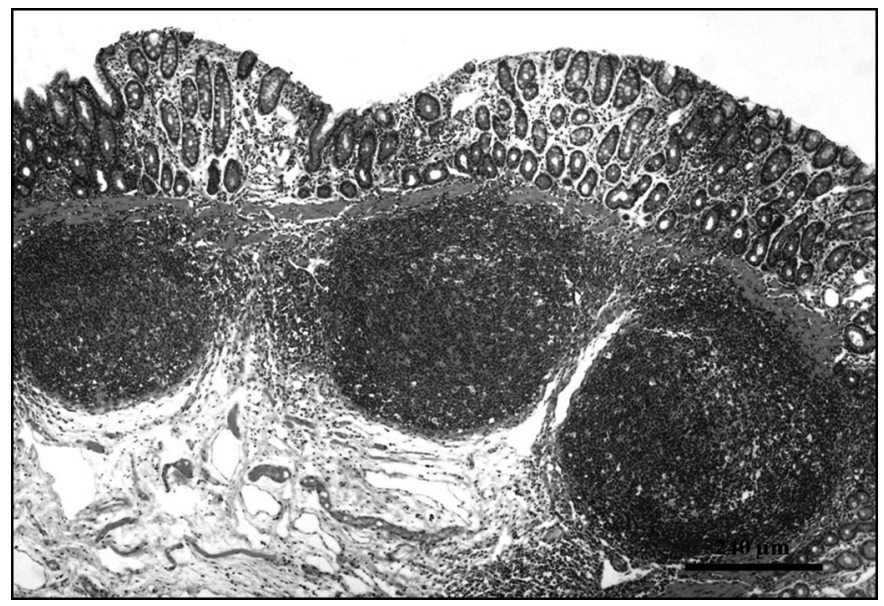

Fig.3. Corte histológico de biópsia de mucosa retal de ovino, folículos linfoides com centro germinativo bem delimitado. HE, obj.10x.

desparafinados e tratados em solução 10\% de peróxido de hidrogênio (Merck, Darmstadt, Germany) em metanol por 20 minutos, lavados em água destilada e tratados com ácido fórmico (Merck, Darmstadt, Germany) por cinco minutos. Posteriormente, realizou-se: a lavagem com água destilada e TBS (Tris base, Tris-HCl, $\mathrm{NaCl}$; DAKO ${ }^{\circledR}$, Carpinteria, USA), por dois minutos; lavagem rápida com $0,1 \%$ de Ttween (Sigma Chemical Co., Saint Louis, USA) diluído em TBS, por um minuto; lavagem em água destilada, por um minuto; recuperação antigênica e eliminação de $\mathrm{PrP}^{\mathrm{C}}$ com proteinase K (DAKO Cytomation, Carpinteria, USA), por um minuto e lavagem em água destilada gelada. Para a diminuição das ligações inespecíficas, utilizou-se leite desnatado (Molico ${ }^{\circledR}$, Nestlé, Brasil) na diluição de 5\%, por 20 minutos, e lavados em TBS, por dois minutos.

Os dois anticorpos monoclonais anti-príon F89/160.1.5 e F99/97.6.1 (VMRD Pullman, EUA) foram diluídos em 1:500 cada um e misturados e os cortes histológicos incubados a $37^{\circ} \mathrm{C} \mathrm{com}$ os anticorpos em câmara úmida por 12 horas. Posteriormente, aplicou-se o anticorpo secundário biotinilado ligado a estreptavidina-peroxidase (DAKO LSAB 2 kit $^{\circledR}$, DAKO Corp., Carpinteria, EUA), por 20 minutos em cada etapa. A reação da IHQ foi revelada com cromógeno 3,3-diaminobenzidina (DAB, DAKO Corp., Carpinteria, EUA) durante um minuto, e as lâminas contracoradas com hematixilina. Como controle positivo, utilizaram-se cortes histológicos de tronco cerebral na altura do óbex, linfonodo mesentérico e tonsila de ovino, comprovadamente positivos para scrapie. Como controle negativo, utilizou-se material de cérebro e órgãos linfoides de ovinos com diagnóstico prévio negativo para scrapie e de cérebro de bovino negativo para encefalopatia espongiforme bovina (EEB).

Diante de resultados positivos na IHQ, realizaram-se cinco repetições da técnica nos mesmos casos. De acordo com as normas do Ministério da Agricultura Pecuária e Abastecimento do Brasil MAPA, todos os animais positivos e seus parentes próximos no rebanho infectado foram sacrificados e necropsiados, e as amostras coletadas foram processadas da mesma forma que as biópsias.

\section{RESULTADOS}

Nas 318 amostras de biópsias analisadas, obteve-se 19 resultados positivos $\left(5,98 \%\right.$ dos ovinos) para $\mathrm{PrP}^{\mathrm{sc}}$ nos folículos de terceira pálpebra. Obtiveram-se folículos linfoides da mucosa retal em 263 biópsias (82,70\% das coletas). Dessas amostras, nenhuma marcação positiva para $\mathrm{PrP}^{\mathrm{Sc}}$ foi obtida no tecido linfoide da mucosa retal.

Baseando-se nos resultados das biópsias de terceira pálpebra, 18 animais positivos para scrapie (um animal positivo em biópsia não foi necropsiado pela morte no período entre a coleta e o abate) e 21 animais parentes jovens onde não foi feito o exame pré-clinico destes no rebanho, foram encaminhados para necropsia.

Os exames de IHQ do material coletado no período post mortem, confirmaram os resultados anteriores pela biópsia de pálpebra dos 18 ovinos analisados (Quadro 1). Foi constatada pela observação de acúmulo granular de $\operatorname{PrP}^{\mathrm{Sc}}$ no corpo de macrófagos dos centros germinativos dos folículos linfoides, com menor intensidade na área adjacente (Fig.4). Determinou-se com os resultados que 100\% das terceiras pálpebras analisadas foram positivas para scrapie; $44,45 \%$ das tonsilas e $27,77 \%$ dos linfonodos mesentéricos também se apresentaram positivas. Não houve marcação positiva para $\mathrm{PrP}^{\mathrm{Sc}}$ nas amostras de SNC e de tecido linfoide de mucosa retal de nenhum dos animais necropsiados. Nas IHQ de 21 animais aparentados dos ovinos positivos para $\mathrm{PrP}^{\mathrm{Sc}}$, obteve-se resultado negativo em todos os exames. Em todas as cinco repetições feitas para cada biópsia positiva se obtiveram resultados positivos na imuno-histoquímica.

\section{DISCUSSÃo}

A detecção do $\operatorname{PrP}^{\mathrm{Sc}}$ no tecido linfoide é útil para a identificação precoce de ovinos afetados por scrapie durante a etapa pré-clínica da doença (González et al. 2008). As tonsilas, o tecido linfoide de terceira pálpebra e os linfonodos retrofaríngeos acumulam quantidades de $\operatorname{Pr}^{\mathrm{Sc}}$ detectáveis por IHQ no início da infecção (Schreuder et al. 1996, O’Rourke et al. 1998, 2000) e são úteis para detectar animais portadores (Driemeier 2007). A coleta destes tecidos é adequada para realização de biópsias e exames post mortem de ovinos (O'Rourke et al. 2000, 2002). Estas áreas contêm um número maior de folículos linfáticos, o que as torna possíveis órgãos de eleição para avaliar ovinos sem sinais clínicos de 
Quadro 1. Resultados imuno-histoquímicos para diagnóstico de $\operatorname{PrP}^{\mathrm{sc}}$ em diferentes tecidos coletado de ovinos por biópsia e após necropsia

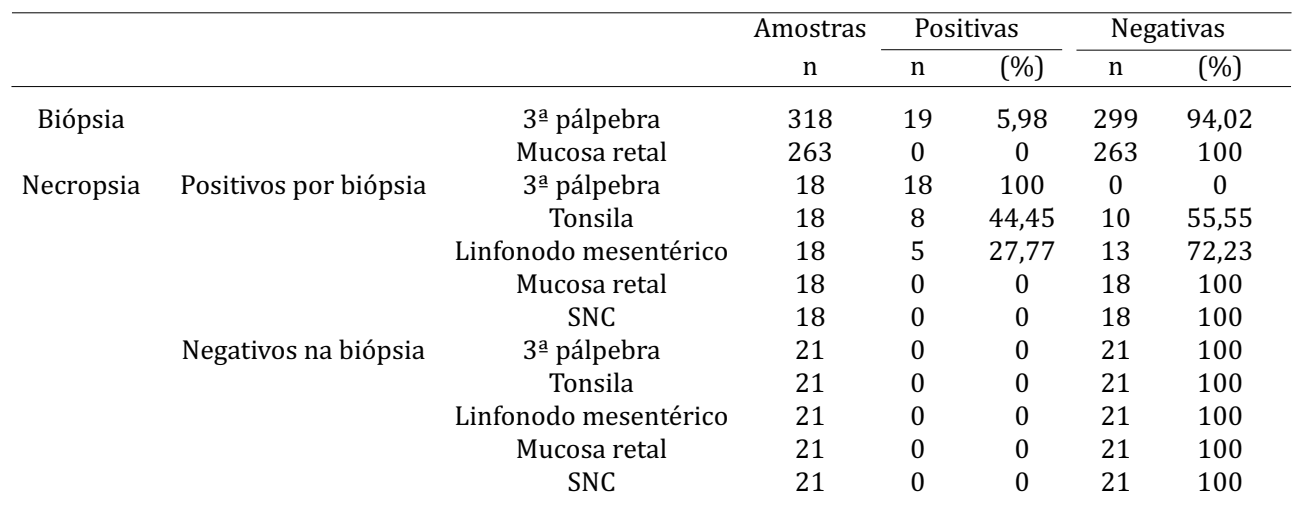

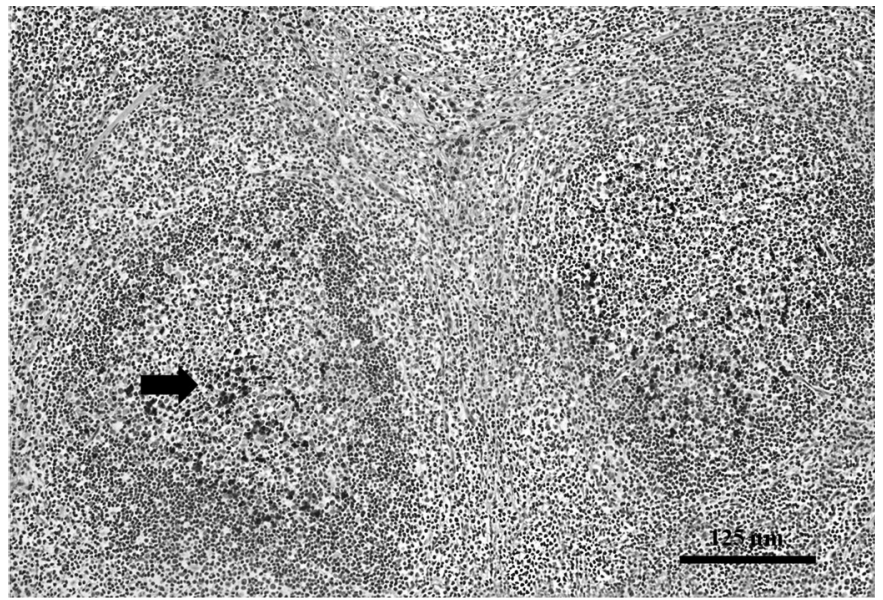

Fig.4. Preparação de imuno-histoquímica para diagnóstico de scrapie, em corte histológico de terceira pálpebra de ovino. Folículo linfoide com intensa marcação positiva para $\operatorname{PrP}^{\mathrm{Sc}}$ no centro germinativo (seta); Obj.20x.

scrapie, combinados com amostras coletadas a partir da medula oblonga, na região do óbex (Driemeier 2007). Conforme observado por Furr et al. (2011) e na IHQ realizada neste trabalho, a distribuição do $\mathrm{PrP}^{\mathrm{Sc}}$ na zona dos centros germinativos de folículos sugere também o envolvimento de células B em infecções priônicas.

Testes para diagnóstico em tecido linfoide são factíveis para o subconjunto das EETs em que $\mathrm{PrP}^{\mathrm{Sc}}$ se acumula nos gânglios linfáticos, principalmente no início do período de incubação (Van Keulen et al. 1996, Furr et al. 2011). De acordo com os resultados obtidos nas coletas realizadas na propriedade estudada, todas as amostras de terceira pálpebra foram positivas para scrapie, sem que os animais apresentassem sinais clínicos. A existência e as implicações das formas subclínicas da doença priônica têm sido discutidas, indicando que os animais propagam e acumulam altos níveis de príons infecciosos, mas podem viver uma vida normal sem exibir sinais clínicos da doença (Race \& Chesebro 1998, Thackray et al. 2002). A compreensão da patogênese envolvida nestas condições neurodegenerativas em um nível molecular é crucial para desenvolver testes de diagnóstico precoce (Hill \& Collinge 2003). Portanto, os animais podem ser assintomáticos com títulos de $\operatorname{PrP}^{\mathrm{Sc}}$ no encéfalo e outros tecidos.
0 aperfeiçoamento da utilização da terceira pálpebra em teste ante mortem para diagnóstico de scrapie e a identificação dos genótipos PrP de animais com doenças subclínica e clínica associadas com acúmulo $\mathrm{PrP}^{\mathrm{Sc}}$, disponibilizaram meios adicionais para controlar a doença em populações ovinas na União Europeia. A estimativa da especificidade do teste de terceira pálpebra é de $100 \%$; a sensibilidade estimada do teste é de 85 a 90\% (O’Rourke et al. 2000).

Os resultados falso-negativos pela análise da mucosa retal são devidos a inúmeros fatores. Aleksandersen et al. (1991) relataram a localização agregada dos folículos linfoides entre pregas longitudinais, na mucosa retal, como uma das causas. Outra possibilidade para a dificuldade no diagnóstico seria a realização da coleta mais caudal à junção reto-anal, que diminui a quantidade de folículos obtidos nas biópsias (Dennis et al. 2009). Esses pontos são importantes, pois a coleta inadequada e em quantidade insuficiente é um limitador para o método de exame com biópsia da mucosa retal.

A limitação de métodos como o Western blotting e ELISA, que são as técnicas mais comumente utilizadas em programas de vigilância de scrapie e EEB na Europa e Estados Unidos, está associada com uma pequena amostra contendo folículos, o que reduz a probabilidade de se obter quantidades detectáveis de $\operatorname{PrP}^{\mathrm{Pc}}$ e aumenta a probabilidade de resultados falso negativos. Nesse aspecto, os testes baseados em IHQ podem ser mais sensíveis e mais fáceis de interpretar, pois a visualização de folículos pode ser facilmente avaliada (Espenes et al. 2006) e a técnica detecta o príon mesmo em pequenas concentrações (Furr et al. 2011).

\section{CONCLUSÕES}

A utilização de tecidos linfoides no diagnóstico de scrapie por IHQ através de biópsias mostrou-se um método viável e eficaz para o diagnóstico pré-clínico.

Entre os órgãos analisados a terceira pálpebra apresentou-se como o principal tecido linfoide para confirmação da enfermidade por biópsia e no exame post mortem.

A identificação dos animais afetados no período pré-clínico é fundamental para o controle do scrapie, eliminando ovinos que poderiam ser potenciais fontes de infecção para outros animais no próprio ou em outros rebanhos. 
Agradecimentos.- À Coordenação de Aperfeiçoamento de Pessoal de Nível Superior (CAPES) pela concessão da bolsa de mestrado e ao Conselho Nacional de Desenvolvimento Científico e Tecnológico (CNPq) pelo auxílio da pesquisa (Proc.578226/2008-1, Proc. 505917/2008-4 e 500506/2011-6) e da bolsa de pós-doutorado (Proc.150903/2011-1).

\section{REFERÊNCIAS}

Aleksandersen M., Nicander L. \& Landsverk T. 1991. Ontogeny, distribution and structure of aggregated lymphoid follicles in the large intestine of sheep. Dev. Comp. Immunol. 15(4):413-422.

Andréoletti O., Orge L., Benestad S.L., Beringue V., Litaise C., Simon S., Le Dur A., Laude H., Simmons H., Lugan S., Corbière F., Costes P., Morel N., Schelcher F. \& Lacroux C. 2011. Atypical/Nor98 scrapie infectivity in sheep peripheral tissues. PLoS Pathog. 7(2):e1001285.

Billinis C., Panagiotidis C.H., Psychas V., Argyroudis S., Nicolaou A., Leontides S., Papadopoulos O. \& Sklaviadis T. 2002. Prion protein gene polymorphisms in natural goat scrapie. J. Gen. Virol. 83:713-721.

Dennis M.M., Thomsen B.V., Marshall K.L., Hall S.M., Wagner B.A., Salman M.D., Norden D.K., Gaise C. \& Sutton D.L. 2009. Evaluation of immunohistochemical detection of prion protein in rectoanal mucosa-associated lymphoid tissue for diagnosis of scrapie in sheep. Am. J. Vet. Res. 70(1):63-72.

Driemeier D. 2007. Scrapie, p.475-484. In: Riet-Correa F., Schild A.L., Lemos R.A.A. \& Borges J.R. (Eds), Doenças de Ruminantes e Equídeos. 3aa ed. Pallotti, Santa Maria.

Espenes A., Press C.M., Landsverk T., Tranulis M.A., Aleksandersen M., Gunnes G., Benestad S.L., Fuglestveit R. \& Ulvund M.J. 2006. Detection of $\mathrm{PrP}^{\mathrm{Sc}}$ in rectal biopsy and necropsy samples from sheep with experimental scrapie. J. Comp. Pathol. 134(2/3):115-125.

Fraser H. 2000. Scrapie in sheep and goats, and related diseases, p.201208. In: Martin W.B. \& Aitken I.D. (Eds), Diseases of Sheep. $3^{\text {rd }}$ ed. Blackwell Science, Oxford.

Furr A., Knudsen D., Hildreth M.B. \& Young A.J. 2011. Enhancement of immunohistochemical staining of scrapie proteins and immune cells within lymph nodes of early scrapie-infected sheep. J. Immunol. Methods 371(1/2):1-7.

González L., Dagleish M.P., Martin S., Dexter G., Steele P., Finlayson J. \& Jefrey M. 2008. Diagnosis of preclinical scrapie in live sheep by the immunohistochemical examination of rectal biopsies. Vet. Rec. 162(13):397-403

Hill A.F. \& Collinge J. 2003. Subclinical prion infection. Trends Microbiol. 11(12):578-584.

Hoinville L. 1996. A review of the epidemiology of scrapie in sheep. Rev. Sci. Tech. 15(3):827-852.
Hunter N. 1997. PrP genetics in sheep and the implicationsfor scrapie and bse. Trends Microbiol. 5(8):331-334.

Ikegami Y., Ito M., Isomura H., Momotani E., Sasaki K., Muramatsu Y., Ishiguro N. \& Shinagawa M. 1991. Pre-clinical and clinical diagnosis of scrapie by detection of PrP protein in tissues of sheep. Vet. Rec. 128(12):271275.

Miller J.M., Jenny A.L., Taylor W.D., Marsh R.F., Rubenstein R. \& Race R.E. 1993. Immunohistochemical detection of prion protein in sheep with scrapie. J. Vet. Diagn. Invest. 5:309-316.

O’Rourke K.I., Baszler T.V., Miller J.M., Spraker T.R., Sadler-Riggleman I. \& Knowles D.P. 1998. Monoclonal antibody F89/160.1.5 defines a conserved epitope on the ruminant prion protein. J. Clin. Microbiol. 36(6):1750-1755.

O’Rourke K.I., Baszler T.V., Besser T.E., Miller J.M., Cutlip R.C., Wells G.A.H., Ryder S.J., Parish S.M., Hamir A.N., Cockett N.E., Jenny A. \& Knowles D.P. 2000. Preclinical diagnosis of scrapie by immunohistochemistry of third eyelid lymphoid tissue. J. Clin. Microbiol. 38(9):3254-3259.

O'Rourke K.I., Duncan J.V., Logan J.R., Anderson A.K., Norden D.K., Williams E.S., Combs B.A., Stobart R.H., Moss G.E. \& Sutton D.L. 2002. Active surveillance for scrapie by third eyelid biopsy and genetic susceptibility testing of flocks of sheep in Wyoming. Clin. Diagn. Lab. Immunol. 9(5):966-971.

Prusiner S.B. 1982. Novel proteinaceous infectious particles cause scrapie. Science 216(4542):136-144.

Prusiner S.B. 1995. The prion diseases. Scient. Am. 272:48-57.

Race R. \& Chesebro B. 1998. Scrapie infectivity found in resistant species. Nature 392(6678):770.

Schreuder B.E.C., Van Keulen L.J.M., Vromans M.E.W., Langeveld J.P.M. \& Smits, M.A. 1996. Preclinical test for prion diseases. Nature 381(6583):563.

Schreuder B.E.C., Van Keulen L.J.M., Vromans M.E.W., Langeveld J.P.M. \& Smits M.A. 1998. Tonsillar biopsy and $\mathrm{PRP}^{\mathrm{sc}}$ detection in the preclinical diagnosis of scrapie. Vet. Rec. 142(21):564-568.

Thackray A.M., Klein M.A., Aguzzi A. \& Bujdoso R. 2002. Chronic subclinical prion disease induced by low-dose inoculum. J. Virol. 76(5):25102517.

Van Keulen L.J.M., Schreuder B.E.C., Meloen R.H., Mooijharkes G., Vromans M.E.W. \& Langeveld J.P.M. 1996. Immunohistochemical detection of prion proteins in lymphoid tissues of sheep with natural scrapie. J. Clin. Microbiol. 34(5):1228-1231.

Wood J.L., Lund L.J. \& Done S.H. 1992. The natural occurrence of scrapie in moufflon. Vet. Rec. 130(2):25-27. 